\title{
LOCATING ASPERITIES BY MEANS OF STOCHASTIC ANALYSIS OF SEISMIC CATALOGS
}

\author{
Arvanitakis K. ${ }^{1}$, Gounaropoulos C. ${ }^{2}$ and Avlonitis M. ${ }^{3}$ \\ ${ }^{1}$ Ionian University, Department of Informatics, 49100, Corfu, Greece, c14arva@ionio.gr \\ ${ }^{2}$ Ionian University, Department of Informatics, 49100, Corfu, Greece, xarisgoun@hotmail.com \\ ${ }^{3}$ Ionian University, Department of Informatics, 49100, Corfu, Greece, avlon@ionio.gr
}

\begin{abstract}
In this study it is proposed that spatially detecting low $b$ values in certain segment faults in conjunction to the spatial earthquake density of the corresponding areas, can be used in order to locate faults asperities. This hypothesis is tested in the area of Corinth Gulf where we have processed data from the earthquake catalog of the Aristotle University of Thessaloniki, during a significant period of 45 years, from 1970 until 2015. From the calculations of b values and earthquake density in certain regions asperity patterns have been observed: asperity located by small $b$ values and low densities coincide with proposition of possible asperity found in literature. Based on these facts we reproduce the hypothesis of an Asperity in the south area of Corinth Gulf between the Helike and Xilokastro faults.

Keywords: Asperities, $b$ value, seismic density.
\end{abstract}

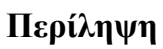

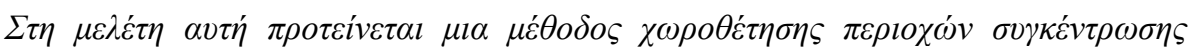

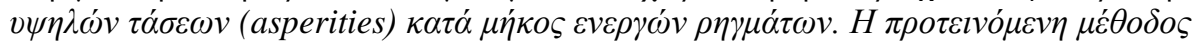

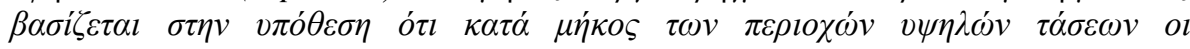

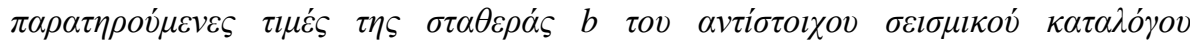

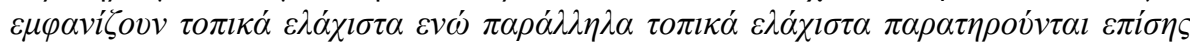

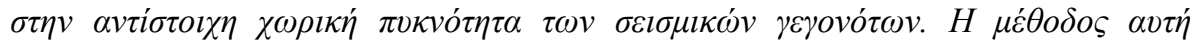

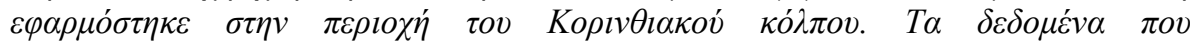

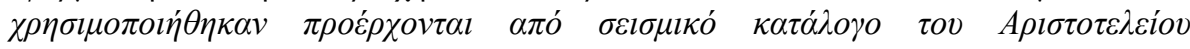

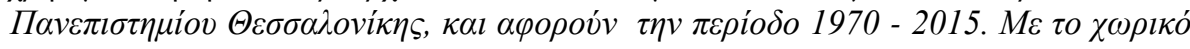

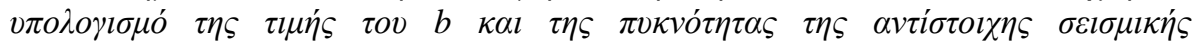

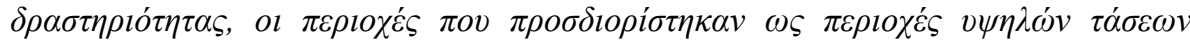

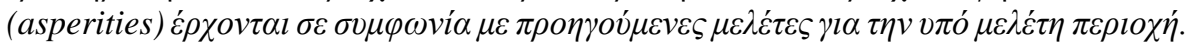

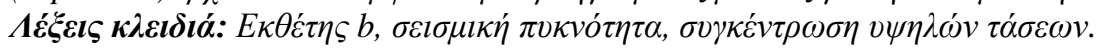

\section{Introduction}

Asperities are considered to be strong patches of varying dimensions on a fault. They have dimensions ranging from less than a kilometer to tens of kilometers. They are locked inside the faults under high pressure and they release most of the energy during the eventual earthquake (Wiemer and Wyss, 1997). 
Being more detailed, this large patch is divided into a numerous subfaults capable of accumulating large amounts of stress. The surrounding areas are not capable of storing the same amount of stress and form a weak zone around the asperity. The tectonic stress increase in the wider area, and the weak zones break more easily than the asperity, creating small earthquakes that many times form a swarm. As the stress increases, all the weak zones break and become seismically quiet. All this time the asperity appears to be inactive. When the limit of stress that the asperity can accumulate is reached, eventually breaks and the main shock is generated (Kanamori, 1981).

There has been noticed that $b$ values are significantly lower in asperities, in comparison with the rest of the fault zone which have higher b values (Wiemer and Wyss, 1997).

The Gulf of Corinth, which is located between continental Greece and Peloponnese, has high seismic activity. This structure is about $2 \mathrm{~m}$.y. old and opens by a rate of $1 \mathrm{~cm} / \mathrm{yr}$. Known from the ancient years serious earthquakes have occurred in this area but only 6 earthquakes of magnitude greater than 6 have been recorded since the instrumental seismology has started (Hatzfeld et al., 1996).

Modern instrumental seismology and scientific earthquake software help us to study this area with more detail and see if there is a connection between normal fault system and a possible asperity (Hatzfeld et al., 1996).

The purpose of this study is to introduce a complementary approach for locating asperities in the Gulf of Corinth along the Xylokastro fault, by means of patterns of low b value and low earthquake density, using only recent data from the earthquake catalog of the broader area.

\section{Seismicity and Location of Asperities}

The map under study was separated in certain areas along the Corinth Gulf in order to examine the spatial variations of $b$ value and earthquake density. To succeed that, we used data taken from earthquake catalog of the Aristotle University of Thessaloniki.

All the measurements in this paper were made with the ZMAP application (Wiemer, 2001). ZMAP was created by Stefan Wiemer in 1994 and it is a graphical interface application, constructed for the MATLAB environment. The purpose of this application is to determine the quality of seismic $\mathrm{d}$ ata, which are included in earthquake catalogs, and also to calculate and extract useful features. The application combines many basic and useful tools for seismological research. In combination with the graphical user interface, ZMAP constitutes a powerful tool in statistic seismological analysis of earthquake catalogs.

The location of an asperity is necessary information in terms of a region's seismicity analysis and gives a perception for the fault surface topography and also the mechanisms which apply in the area.

There are two popular methods of how to locate an asperity. Since by definition an asperity is a high stress area surrounded by low stress areas, the first method calculates the stress levels of a region and points the areas with higher levels (Hatzfeld et al., 1996; Park and Mori., 2007; Dalguer et al., 2003). That method was used in Corinth's Gulf (Hatzfeld et al, 1996) reaching to the conclusion that there is an asperity between the Helike and Xilokastro faults, because that area has higher stress level than the surrounding areas.

The other method uses the surface's slip. By using GPS data of the slip distribution on the earth's surface, the asperities are located in regions where big deformations are detected (Pulido, 2004; Irikura et al., 2004; Ozacar and Beck, 2005; Kagawa et al., 2004; Murotani et al., 2013; Spence et al., 1999; Pulido et al., 2008).

In a recent study which concerns the region of Hokkaido (Japan), (Takahashi and Kasahara, 2013) the authors proposed a method for locating asperities by means of the earthquake's density. As asperities were selected sections of the region with small number of events, at least one event with high magnitude, and surrounded by sections with large number of events. 
The examined region in this paper is the Corinth Gulf. It is one of the most seismically active regions of Greece, and constitutes a continental rift by separating Peloponnese from central Greece, extending from Gulf of Patras to Gulf of Alkionides in a total distance of $120 \mathrm{~km}$ approximately (Giannopoulos et al., 2014).

The three main faults, in the Gulf, are the Psarhopyrgos, the Helike and the Xylokastro faults. Also there are many other smaller faults in Corinth Gulf. In the East part there is Loutraki and Kaparelli faults, Delphi, Erithres and Antikira faults in the Center, and in the West the Gulf is connected through Rio-Antirio with the Gulf of Patras but there are no major faults that affect the Corinth Gulf (Hatzfeld et al., 2000). The extension rate of the faults, measured by GPS, is about $10 \mathrm{~mm}$ year-1.

\section{Data-set}

The data used in this study were taken from the Greek National Seismological Network and were compiled from the bulletins of the Central Seismological Station of Geophysics Department of the Aristotle University of Thessaloniki (http://geophysics.geo.auth.gr/ss/). The completeness of the data set was checked using the Gutenberg-Richter relation and the minimum magnitude above which the sample is complete was found equal to 3. Moreover the catalog's completeness was checked within consecutive 5-year time intervals. The catalog's data covers a region with latitude 37.9 to 38.6 and longitude 21.4 to 23.3 . The first event recorded is from 5/01/1970 and the last one from 20/01/2015. The overall number of events in this catalog is 8696 . The smallest recorded magnitude is 3.0 and the largest one 6.7. In total there are 8 events with magnitudes greater or equal to 6.0 , and 43 events between 5.0 and 5.9. The background $b$ was 1.33 as it can be seen in the GRFMD.

\section{The proposed methodology and results}

For the purposes of this paper the wider area of Corinth's Gulf was separated in a grid by 0,1 latitude and longitude degrees. The measurements were used where only from the cells that had at least 50 earthquake events in order to ensure the robustness of the estimate $b$ values. The radius of every cell that had at least 30 events was increased in order to contain 50 events, using the data of the surrounding cells.

For all those sections the number of events (density) and $\mathrm{b}$ value were calculated. For all measurements the software ZMAP was used, while for the $b$ value estimation the Maximum likelihood method was chosen.

In the formula that describes the G-R FMD [Equation 1] the b value constitutes the slope of the distribution and describes the ratio of small and big earthquakes in an earthquake catalog (Kulhanek, 2005). The most often procedures used to calculate the $b$ value of a G-R FMD is the Maximum Likelihood Estimate of b (Aki, 1965) method created by Utsu and the least square technique (Gutenberg and Richter, 1944). For the purposes of this research, ZMAP was set to calculate the b value by using the Maximum Likelihood technique. With this method $\mathrm{b}$ value is given by [Equation 2] where $M_{\mu}$ is the mean magnitude of earthquakes and $M c$ is the magnitude of completeness of the catalog.

\section{Equation 1 - Gutenberg - Richter frequency magnitude relation}

$$
\log (N)=a-b * M \text {. }
$$

\section{Equation 2 - Formula for the estimation of $b$ value}

$$
b=\log (e) /\left(M_{\mu}-M_{\mathrm{c}}\right)
$$

The results derived by Zmap were plotted in two contour maps. In Figure 1 the spatial distribution of the density of earthquake events greater than 3.0 is shown. It can be seen that there are three areas 
with significantly lower density compared to neighbourhood values, plotted with dark blue colour. It should be noted that according to the study of (Takahashi and Kasahara, 2013), these areas coinside with the location of asperities. According to the idea proposed in this study and in order to address this discrepancy of the proposed methodology of (Takahashi and Kasahara, 2013), we introduce as a complementary indicator the spatial distribution of b value Figure 2. It can be seen in Figure 3 that combining the areas of low density value as well as low b values, only the areas A and $\mathrm{C}$ highlighted with green strokes satisfy both requirements. These findings strongly suggest that in the wider area of 22.3 Longitude and 38.1 Latitude an asperity is located. Moreover in this area it is also proposed by (Hatzfeld et al., 1996) that an asperity is located. Additionally we propose that another asperity is located in the wider area of 21.4 Longitude and 38.4 Latitude a proposal that should be explored in a future study.

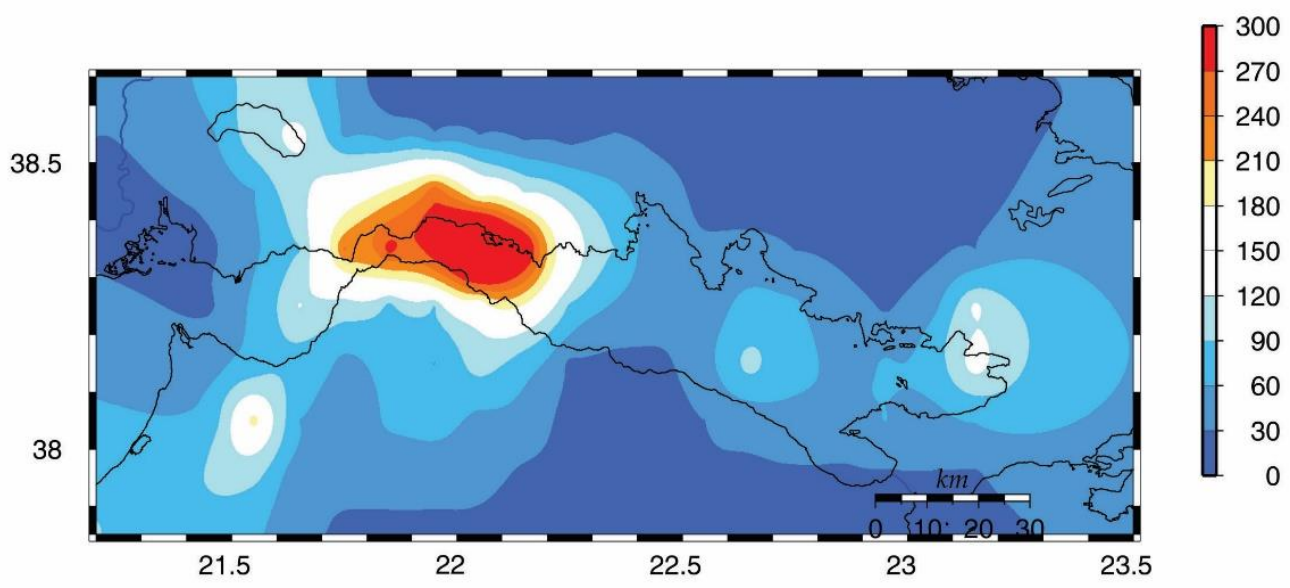

Figure 1 - Contour map of earthquake density in Corinth's Gulf.

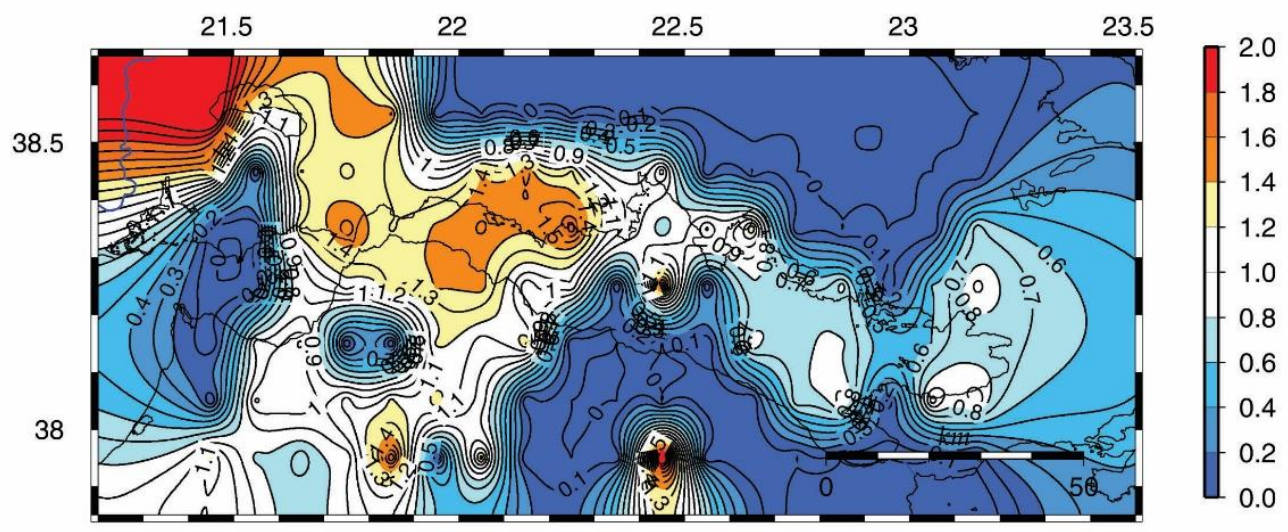

Figure 2 - Contour map of b-value in Corinth's Gulf. 


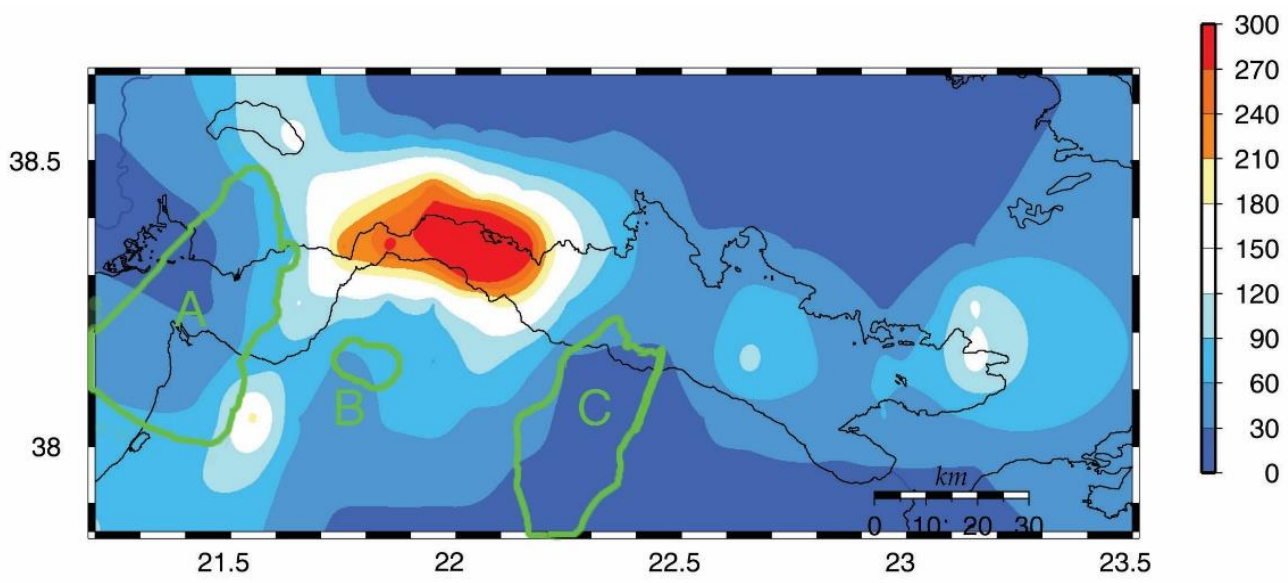

Figure 3 - Contour map of earthquake density in Corinth's Gulf, overlapped with areas of low b value.

\section{Conclusion}

In the wider region of Corinth's Gulf, spatial variations of density and b value were mapped in a 0,1 degree grid. In a previous research (Hatzfeld et al., 1996) proposed that there is an asperity located between the Helike and Xylokastro faults placed in the south section of Corinth's Gulf. From our calculations it appears that three sections have a significant low density, indicating the existence of asperities as was proposed by (Takahashi et al., 2013) and which is in contradiction with the study of (Hatzfeld et al., 1996) suggesting the existence of only one asperity. However a patch of low b value is found only in the area between the Helike and Xilokastro faults. These facts according to our proposition strongly suggest that an asperity is located in this area and comes in agreement with (Hatzfeld et al., 1996) study. As it seems the extracted information of the b value mapping can correct false indications coming from the method proposed by (Takahashi et al., 2013).

As a result, the complementary estimation of spatial areas with low b value as well as low density values may serve as a valuable tool in robust estimation of asperities locations within a specific seismogenic zone. Moreover, for more complex seismogenic zones, the use of more than two spatial indicators may be appropriate. As an example the estimation of the spatial variability of recurrence time may also serve as a bust indicator for locating asperities, as was proposed in (Wyss et al., 2000).

\section{Acknowledgments}

Fruitful discussions with Professor Eleftheria Papadimitriou are gratefully acknowledged.

\section{References}

Aki, K., 1965. Maximum Likelihood Estimate of $\mathrm{b}$ in the Formula $\log \mathrm{N}=\mathrm{a}-\mathrm{bM}$ and its Confidence Limits, Bulletin of the Earthquake research Institute, 43, 237-239.

Dalguer, L.A., Irikura, K. and Riera, J.D., 2003, Simulation of tensile crack generation by threedimensional dynamic shear rupture propagation during an earthquake, Journal of Geophysical Research: Solid Earth, 108.

Giannopoulos, D., Sokos, E., Konstantinou, K.I. and Tselentis, G.A., 2014. Shear wave splitting and VPVS variations before and after the Efpalio earthquake sequence, western Gulf of Corinth, Greece, Geophysical Journal International, 1436-1448.

Gutenberg, B. and Richter, C.F., 1944. Frequency of Earthquakes in California, Bulletin of the Seismological Society of America, 34, 185-188. 
Hatzfeld, D., Karakostas, V., Ziazia, M., Kassaras, I., Papadimitriou, E., Markopoulos, K., Voulgaris, N. and Papaioannou, C., 2000. Microseismicity and faulting geometry in the Gulf of Corinth (Greece), Geophysical Journal International, 141, 438-456.

Hatzfeld, D., Kementzetzidou, V., Karakostas, V., Ziazia, M., Nothard, S., Diagourtas, D. Deschamps, A., Karakaisis, G., Papadimitrio, P., Scordilis, M., Smith, R., Voulgaris, N., Kiratzi, S., Makropoulos, K., Bouin, M.P. and Bernard, P., 1996. The Galaxidi Earthquake of 18 November 1992. A Possible Asperity within the Normal Fault System of the Gulf of Corinth (Greece), Bulletin of the Seismological Society of America, 86, 1987-1991.

Irikura, K., Miyake, H., Iwata, T., Kamae, K., Kawabe, H. and Dalguer, A., 2004. Recipe for Predicting Strong Ground Motions from Future Large Earthquakes, 13th World Conference on Earthquake Engineering.

Kagawa, T., Irikura, K. and Somerville, P.G., 2004, Differences in ground motion and fault rupture process between the surface and buried rupture earthquakes, Earth Planets Space, 56, 3-14.

Kanamori, H., 1981. The Nature of Seismicity Patterns Before large Earthquakes, Earthquake Prediction.

Kulhanek, O., 2005. Seminar on b-value, Dept. of Geophysics, Charles University, Prague.

Murotani, S., Satake, K. and Fujii, Y., 2013. Scaling relations of seismic moment, rupture area, average slip, and asperity size for $M \sim 9$ subduction-zone earthquakes, 40.

Ozacar, A., and Beck, S.L., 2005. The 2002 Denali Fault and 2001 Kunlun Fault Earthquakes: Complex Rupture Processes of Two Large Strike-Slip Events, Bulletin of the Seismological Society of America, 278-292.

Park, S.C. and Mori, J., 2007. Are asperity patterns persistent Implication from large earthquakes in Papua New Guinea, Journal of Geophysical Research: Solid Earth, 112.

Pulido, N., 2004. Broadband Frequency Asperity Parameters of Crustal Earthquakes From Inversion of Near-Fault Ground Motion, 13th World Conference on Earthquake Engineering.

Pulido, N., Aoi, S. and Fujiwara, H., 2008. Rupture process of the 2007 Notohanto earthquake by using an isochrones back-projection method and K-NET/KiK-net data, 60, 1035-1040.

Spence, W., Mendoza, C., Engdahl, E.R., Choy, G.L. and Norabuena, E., 1999. Seismic Subduction of the Nazca Ridge as Shown by the 1996-97 Peru Earthquakes, Pure and Applied Geophysics, 154, 753-776.

Takahashi, H. and Kasahara, M., 2013. Spatial Relationship Between Interseismic Seismicity, Coseismic Asperities and Aftershock Activity in the Southwestern Kuril Islands, Volcanism and Subduction: The Kamchatka Region.

Wiemer, S., 2001. A software package to analyze seismicity: ZMAP, Seismological Research Letters, 72.

Wiemer, S. and Wyss, M., 1997. Mapping the frequency-magnitude distribution in asperities: An improved technique to calculate recurrence times? Journal of Geophysical Research, 102, 115-128.

Wyss, M., Schorlemmer, D. and Wiemer, S., 2000. Mapping asperities by minima of local recurrence time: San Jacinto-Elsinore fault zones, Journal of Geophysical Research, 105, 7829-7844. 